\title{
Desvelando a Criança que Existe em seu Aluno, Algumas Implicaçōes para $O$ Fazer da Professora Pré-Escolar
}

\author{
Maria das Graças Fleury*
}

\section{RESUMO}

Este artigo traz os dados e as discussões de uma pesquisa realizada sobre as representações de Crianças, Infância e Aluno, que professoras de pré-escola expressam a partir de um conjunto de técnicas gráficas, observacionais e orais.

A representação que a professora pré-escolar faz de seu aluno é a mesma que ela faz da criança? Qual é essa representação? O que essa representação vem influenciar o seu dia-a-dia em sala de aula? Essa representação está ligada a outras representações, como por exemplo, de aluno e à representação do papel de professora? Está ligada também com a concepção do processo ensino-aprendizagem?

Todas essas perguntas embasaram e também foram surgindo no decorrer de uma pesquisa realizada em uma pré-escola da rede de um bairro periférico do município de Goiânia-GO. Essa pesquisa utilizou diferentes meios para a coleta de dados com a finalidade de realmente tentar conhecer e compreender o tipo e qual representação que a professora tem da criança, sua aluna, e não só o que ela verbaliza, isto é, o que é aparente em sua fala.

Antes, porém, é preciso explicar em que acepção o termo representação será usado, pois este termo é amplamente recorrido pelas Ciências Sociais, pela Psicologia e diversas correntes psicanalíticas. Representação, para nós, é uma organização composta de uma multiplicidade de impressões recobertas pelo sistema coletivo e simbólico que abrange imagens de nossas vidas, provindas das mais diferentes fontes referentes a um determinado objeto da realidade social. Os conceitos de mito, opinião e imagem têm aproximação com o conceito de representação, mas eles são diferentes. Sendo o conceito de representação considerado um "constructo" e, por isso, trazendo implícita a conotação de seguimento ou processo e visando conseguir a compreensão da representação que a professora tem de criança, adotaramse diversos meios para coleta de dados, pois que é difícil tentar apreender estas representações de um espaço temporal delimitado.

* Mestre; Diretora-Fundadora do Centro Educativo Piaget, Goiânia-Go; Doutoranda em Psicologia pela USP-SP, Ribeirão Preto. 
Dentro de uma abordagem qualitativa, os meios usados foram:

- a caracterização das professoras pesquisadas, das crianças e o seu contexto escolar;

- observação em sala de aula e fora dela na tentativa de captar o aspecto formal e o informal (o cafezinho, as atividades do pátio, a chegada e a saída das crianças, o contato destas com a professora nos corredores, etc.);

- entrevistas abertas, mais parecidas a uma conversa informal entre a pesquisadora e as professoras sobre um dia de aula, como foi a última semana, reminiscências da primeira escola, da primeira professora, da própria infância, etc.;

- desenhos realizados pelas professoras, do conceito de criança e do papel do educador ante essa criança na tentativa de aprofundar os conceitos emitidos durante as entrevistas e passá-los do nível de representação verbal para outro nivel não verbal;

- associação livre com a palavra criança. Depois de ouvir a palavra criança a professora deveria imediatamente falar todas as palavras que the viessem à mente;

- afirmações inacabadas que deveriam ser completadas pelas professoras importando tão somente a sua sinceridade, aquilo que realmente pesam, deixando bastante claro que aquilo não seria um teste de inteligência ou caráter, com respostas certas ou erradas, boas ou más;

- grupo de debates onde foram lidos textos que polemizam a questão do respeito dedicado à criança e o mito da plena felicidade infantil seguidos de discussões para aprofundar os dados colhidos anteriomente com os diferentes meios descritos acima;

- por último, entrevista final para, depois de todos estes encontros durante alguns meses, olhar para tudo o que foi feito anteriomente, dar um retorno às professoras informantes, checar alguns pontos, etc.

Todas essas diferentes técnicas (meios) geraram dados valiosos para se conhecer a representação de criança que a professora tem. Não podemos apontar uma técnica como sendo mais importante que a outra. Todas fornecem dados imprescindíveis, além do mais, os dados provenientes de diferentes fontes se complementaram.

Ao analisar todos os dados provenientes das diversas fontes (segundo os diferentes meios adotados) constatei a impossibilidade de se imobilizar, em classificação definida, a representação pessoal de cada professora. Foi preciso esforço para aceitar e compreender a dinâmica das diferentes representações que surgiram.

No decorrer da pesquisa e da respectiva análise, feita concomitantemente, e sobretudo após a reunião dos dados, desvelou-se, para mim, que representar a criança ou um estado (a infância) não é simplesmente repetir ou reproduzir sua própria infância, mas reconstituí-la, aproveitando todas as imagens, significados, conceitos, crenças, percepções, lembranças, 
opiniões e vivências que uma pessoa tem sobre infância/criança. Quero dizer - representação é uma reapresentação, que tem algo diferente do objeto apresentado e que tèm algo igual ẹ conservado deste mesmo objeto, numa construção em parte derivada do social onde a pessoa está inserida. Assim, ao mesmo tempo, ela é subjetiva e objetiva - é individual e coletiva.

Desta maneira, a representação de criança contém várias nuances e não é estática, sendo complexa e com traços contraditórios. Não é possível falar que determinada professora tenha uma representação romantizada ou idealizada acerca de criança, ou que outra tenha uma representação realista. A maior parte das professoras demonstrou, em suas falas, mais elementos que tendem para a dimensão romantizada: apontaram para a criança somente adjetivos bons, indicando pureza, meiguice, inocência, etc. Contraditoriamente, as atitudes das professoras observadas, não só nas salas de aula (aspecto formal) como também nas situações informais, são atitudes pedagogizantes, moralistas, normativas. Isto coincide com as análises de B. Charlot (1983, p.244) sobre os sistemas pedagógicos: na pedagogia tradicional, o adulto deve guiar a criança, domar sua natureza, impor-lhe regras, apresentar-lhe modelos ideais, não ocorrendo o mesmo na pedagogia nova.

A análise que me parece mais próxima da realidade observada é que, para elas, a criança enquanto dimensão abstrata, constructo a- histórico, é essencialmente boa, pura, inocente, criativa, espontânea etc. Por outro lado, quando elas se referem à criança concreta, que está á sua frente, ressaltam sua precária condição de vida, sem recorrer aos adjetivos (boa, pura...) citados anteriormente, mesmo confirmando que há uma essência ou natureza infantil em todas as crianças, independente do estrato social a que pertencem.

O pensamento das professoras (até mesmo de uma só professora) corresponde, ao nosso ver, a uma curiosa fusão do famoso pocma romântico de Casimiro de Abreu, "Meus 8 Anos", e a fina ironia encontrada na paráfrase desse poema feito por Ruth Rocha "Ai que saudades..." (lextos usados para o grupo de debates). Esse paradoxo não pode ser visto como a imagem que cada um de nós tem da infância (sobretudo da nossa própria)? Isto é, a doçura da lembrança amenizada pelo tempo, contrastando-se com a memória de fatos reais, que em algumas vezes foram muito doloridos? Isto não conduz a uma tentativa de aceitação (muitas vezes inconsciente) da realidade contraditória e complexa que vivenciamos no nosso dia-a-dia de ser pessoa ao mesmo tempo adulta que tem um pouco de criança? De lembranças boas/ruins? Do trabalho com crianças? Alunos e o conflito deste conjunto do fundo de cada um de nós? Estes postos não estão explicitados na lógica paradoxal do pensamento dialético?

Pergunto-me por que foi constatado, nas falas das professoras, um maior número de elementos que tendem para uma dimensão romantizada se elas estão, diariamente, lidando com crianças que elas próprias descrevem como carentes, sofridas e marginalizadas? Como já foi dilo anteriomente, parece-me que a insistência dessa idealização no tocante à criança talvez possa ser interpretada de duas formas que se entrelaçam. A primeira indica a 
possibilidade de o adulto projetar na criança suas aspirações e desejos, resguardando em si a criança mítica que existe em cada um de nós e não se quer que morra. E a segunda interpretação aponta no sentido de que, conservando a criança como inocente, boa, ativa, ficaria mais fácil, para a professora, suportar o seu dia-a-dia, o sentimento de impotência que algumas conseguiram verbalizar, em muitas ocasiões.

De maneira geral, o modo como a professora age em sala de aula está de acordo, como já dito, com a descrição que B. Charlot faz da imagem da criança na pedagogia tradicional. O que se pode acrescentar ao pensamento deste autor é que, como "representação"é um constructo composto de uma multiplicidade de impressões, o fazer pedagógico destas professoras não é um bloco monolítico, ele é sujeito portanto, a infiltrações de suas próprias vivências, lembranças, concepções. Assim, primordialmente, a preparação psicológica é indispensável aos professores primários - nas palavras de J. Piaget (1976, p. 131) "cujo ensino é, deste ponto de vista, visivelmente mais complexo e difícil que um ensino secundário".

Com cfeito, a indicação decorrente deste estudo é exatamente a preparação dos docentes para este nivel, no que concerne a sua própria infância, suas reminiscências e como são vividas no atual momento, bem como as interferências no relacionamento interpessoal com suas crianças/alunos. Fazendo isto, a professora levada a se colocar no lugar de criança, a recordar como ela própria aprendeu, suas dificuldades, seus primeiros dias na escola, suas recordações etc. não estaria desenvolvendo uma maior capacidade empática que facilitaria e promoveria uma real interação entre ela e a criança? Nesse momento, seria bastante pertinente uma reflexão sobre o ser criança como ser social incluso dentro de uma determinada sociedade e sua idcologia. Esta indicação se faz preeminente, visto que as representações das professoras são (em grande parte) idealizadas e ideologicamente comprometidas. Também seria oportuno mostrar como essas representações vão se modificando através dos tempos em consonância com as transformações sócio-econômicas.

Todas as professoras concordam que existe uma essência e/ou natureza infantil. É preciso saber distinguir a essência infantil como dado natural baseado na faixa etária e seu desenvolvimento biológico e a essência infantil que serve como dissimuladora da desigualdade social em que a criança vive enquanto pessoa afastada do processo de produção. Toda criança, em uma sociedade industrial, depende da mediação do adulto. A questão é que o tratamento que se dispensa à criança através dessa mediação é realizado de modos diversos, dependendo de sua condição social. Muitas vezes este tratamento ocorre de formas até opostas.

Seu caráter ideológico apóia-se na essência/natureza infantil, ao tratar todas as crianças de modo igual, não levando em consideração sua condição social. Em outras palavras, a criança, sendo portadora de uma essência infantil, deve receber um tratamento unificado, o que mistifica e encobre as desigualdades sociais existentes.

A qualidade de vida da grande maioria da população infantil hoje, em 
uma sociedade capitalista, é precária; essa sociedade, contudo, apresentase negligente não só para com as crianças, mas também para com os veIhos, os excepcionais, os "improdutivos". de maneira geral. Tal fato também ocorre para com a Natureza implicando em uma exploração incauta, depredativa, poluindo o ar e os rios, além do mal uso da energia nuclear, que tanto serve para preservar a vida, com para destruí-la.

Em outra linha, este estudo chegou a conclusões semelhantes às do estudo de Okuda (1985) sobre a percepção pouco clara do conceito de criança, de aluno e de escola que a professora primária (no meu trabalho, professora de pré-escola) tem. Essa estudiosa levanta questão do tipo: quais as consequências, sobre a criança, do fato de a professora tratá-la como se fosse adulta? Isto não constituiria mais uma da variáveis (dentre as inúmeras já levantadas) que afetam o desempenho do aluno? (Okuda, 1985, p. 312). Pode-se constatar, através das falas das próprias professoras, a diferença entre o conceito de criança e de aluno. "Criança é vida, alegre, saudável, expansiva", "O aluno é estudioso, bem comportado, interessado". Com essas assertivas podemos formar uma imagem de que a criança, ao cruzar a porta da sala de aula, deve deixar de ser criança e passar a ser aluno (evidenciando características mais relacionadas ao adulto). Depois da realização da minha pesquisa, poder-se-ia acrescentar o seguinte pensamento de Okuda - o modo como a professora representa a criança está intimamente ligado ao modo como a professora representa o aluno, a escola, o seu papel de professora e concebe o processo de aprendizagem e o objetivo dessa aprendizagem ou, em outras palavras, da relação entre o sujeito cognoscente e o objeto de conhecimento. Para acentuar ainda mais essa visão de criança interligada à concepção de aprendizagem, aparecem estereotipias nas falas das professoras. Uma disse: "cada professora molda seus alunos do seu jeito, criança é igual a argila". Outra professora acrescentou: "Criança é igual a uma sacolinha, vai enchendo...". Outra ainda disse: "A criança não nasce má, pode passar a ser se você deixar". O que quer dizer que não somente no aspecto cognitivo a criança é uma "tábula rasa", ela também o é no aspecto moral.

Essa reflexão epistemológica traria implicações que incidiriam não na introdução de novas técnicas, práticas, receitas ou métodos em sala de aula, mas sim na reconceituação dos objetivos a serem alcançados.

Quando digo reconceituação dos objetivos a serem alcançados pelas professoras, quero fazer implicar, inclusive, na reconceituação da imagem que o professor tem de, ele próprio, ser um bom professor. Juntando dados surgidos em diferentes momentos da pesquisa, pude constatar que a concepção sobre ser uma boa professora é a daquela que diz o que o aluno deve fazer, como deve fazer, o que deve pensar e o que deve dizer. Em outras palavras, a professora deve ensinar tudo, as crianças devem repetir o que foi ensinado - assim é que se "realiza a aprendizagem" ( $\mathrm{cm}$ sua conceituação).

A outra imagem que se deveria ter de um bom professor seria aquela em que o professor pergunta e encoraja a criança a dizer o que ela realmente pensa; que propõe, que deixa espaço e tempo para a criança coordenar 
pontos de vista diferentes; que dá espaço para a criança relacionar os novos conhecimentos com os que já possui; que aceita o "erro" não como "erro", mas como hipótese a ser testada; quie consiga descentrar dos seus pontos de vista e possa imaginar o que se passa nas cabeças das crianças.

Consequentemente, a criança seria tratada não como um par de olhos, um par de ouvidos e mão e um aparelho fonador que emite sons. Também não seria considerada um anjinho ou coisinha, isto é, uma essência, mas sim, ela seria considerada um ser que pensa, que constrói interpretações e age sobre o real.

Enfatizando, a implicação mais importante das conclusões desta pesquisa para um verdadeiro trabalho da professora pré-escolar é a necessidade de reservar um tempo para desvelar a criança que existe em seu aluno e também de dedicar-se ao conhecimento de sua própria representação de criança, de aluno, do papel da professora, checando-a, discutindo-a e refletindo sobre a ideologização dessa representação.

Não que se queira que a professora tenha um só determinado tipo de representação, mas ao se referir sobre esse assunto, a professora conscientizase de seu modo de pensar a criança, de ver a criança e consequentemente desvelará que determinações a influenciam no seu modo de tratar a criança. Nesta reflexão e possível discussão com outras professoras, vários mecanismos que estão subjacentes às nossas ações docentes teriam chance de serem conhecidos, trabalhados e melhor atendidos. Tudo isso viria facilitar o trabaIho diário da professora, vez que haveria uma preparação psicológica (ao menos em parte) para o desempenho de suas funções.

\section{BIBLIOGRAFIA:}

ABREU, Cassimiro (1947) - Obras Completas de C. de Abreu, Rio de Janeiro, Editora Zélio Valverde S.A. (Coleção "Grandes Poetas do Brasil").

CHARLOT, B.A. (1983) - A Mística Pedagógica, Rio de Janeiro, Edilora Zahar.

OKUDA, M.M. (1985) - Conceito de Criança e Aluno entre Professores de $1^{\circ}$ Grau. Dimensões Semânticas Através de Análise Fatorial, São Paulo, USP (Tese de Doutorado).

PIAGET, Jean. (1976) - Psicologia e Pedagogia. 4 ed., Rio de Janeiro, Editora Forense Universitária.

ROCHA, Rute. (1983) - Ai Que Saudades... In: ABRAMOVICH, F. (org.). O mito da Infância Feliz. São Paulo. 


\section{ABSTRACT}

This paper summarizes the data discussions of one research with preschool teachers and in intended to know their representations about Child, Infancy and Pupil, using a "pool"of techniques to collect data that included the Observational, the Oral and the Grafhic (Drawings). 
